\title{
Text Me! New Consumer Practices and Change in Organizational Fields
}

\author{
Shahzad (Shaz) Ansari \\ Judge Business School, University of Cambridge, Cambridge CB2 1AG, United Kingdom, \\ s.ansari@jbs.cam.ac.uk \\ Nelson Phillips \\ Imperial College Business School, London SW7 2AZ, United Kingdom, n.phillips@imperial.ac.uk
}

\begin{abstract}
$\mathrm{W}$ hile scholars have provided increasingly well-developed theoretical frameworks for understanding the role of institutional entrepreneurs and other purposeful actors in bringing about change in organizational fields, much less attention has been paid to the role of unorganized, nonstrategic actors in catalyzing change. In particular, the role of consumers remains largely uninvestigated. In this article, we draw on a case of the introduction of text messaging in the United Kingdom to explore the role of consumers in catalyzing change in organizational fields. Text messaging has become a widely diffused and institutionalized communication practice, in part changing mobile telephony from a voice-based, aural, and synchronous experience to a text-based, visual, and asynchronous experience. As consumers innovated and diffused new practices around this product, their actions led to significant changes in the field. We suggest how and under what conditions consumers are likely to innovate at the micro level and, with the subsequent involvement of other actors, catalyze change at the field level. Our primary contribution is to show how the cumulative effect of the spontaneous activities of one important and particularly dispersed and unorganized group can lead to changes in a field. By showing how change can result from the uncoordinated actions of consumers accumulating and converging over time, we provide an alternative explanation of change in organizational fields that does not privilege purposeful actors such as institutional entrepreneurs.

Key words: institutional theory; consumers; creation and diffusion of practices; field-level change; mobile telephony; text messaging; case study

History: Published online in Articles in Advance December 29, 2010.
\end{abstract}

\section{Introduction}

Remember who really discovered the power of SMS? How many of us spotted the potential? Let's be honest, none of us. It was our customers who tried it out, found a use for it and started texting in the billions.

(CEO of major mobile operator $\mathrm{mmO}$, keynote address at the Financial Times World Communications Conference, May 10, 2004)

Although the primary focus in institutional analysis has traditionally been stability and isomorphism, researchers over the last two decades have become increasingly interested in change and, in particular, in change in the institutional characteristics of an organizational field and its constituents (Dacin et al. 2002, DiMaggio 1988, Hargrave and Van de Ven 2006, Sauder 2008, Seo and Creed 2002). Although much of the research to date has focused on the role played by purposeful actors such as core organizations, peripheral organizations, professional associations, and the government in spearheading change in fields (e.g., Greenwood and Suddaby 2006, Hensmans 2003, Scott 2001), some writers have also begun to highlight the fact that the role of actors in change is not limited to purposeful action by organized actors. Instead, an unorganized group of individuals can also inadvertently trigger change in an organizational field through their everyday activities. These actors generate change through "partaking" when their autonomous and uncoordinated activities accumulate and converge over time, leading to a situation where "no single individual or organization can be identified as responsible for the change" (Dorado 2005, p. 400; Van de Ven et al. 1999). Partakers act as a collective, not intending to change institutions outright, but rather generating change through their cumulative actions (Dorado 2005). For instance, the uncoordinated actions of numerous unorganized actors, such as amateur radio operators, manufacturers of small radio parts, and "hucksters," played a key role in transforming the radio from a pointto-point to a mass broadcasting communication medium (Leblebici et al. 1991).

Yet institutional theory continues to primarily theorize about the role of purposeful actors in field change (Scott 2001). Although scholars have paid some attention to how certain kinds of unorganized actors can catalyze change in an organizational field through their everyday activities (Munir et al. 2007), the role of consumers in particular has received almost no attention from institutional theorists. This is a surprising omission given the 
fact that consumers are a unique and integral part of an organizational field (DiMaggio and Powell 1983) and can play a central role by creating, diffusing, and legitimizing micro practices that cumulatively "bubble up" and implicate organized actors, creating a groundswell for change at the field level.

Our paper addresses this gap by presenting the results of a case study offering important insights into how consumers establish new practices around a product, resulting in pressure for change that implicates organized actors at the field level. More specifically, we examine the phenomenon of text messaging-two-way alphanumeric communication through mobile phoneswhich, building on the short messaging service (SMS) in mobile telephony, quickly became not just a widely diffused communication practice (much more widespread than e-mailing, for instance), but also became highly institutionalized, ${ }^{1}$ catalyzing change at the field level. Whereas the practice of mobile telephony is built around "talk," SMS involves communicating through text rather than voice, changing mobile telephony from an aural to a visual experience (Fortunati 2002) and providing a valuable research site for understanding the dynamics of change in an evolving field.

Through our in-depth examination of the evolution of the field of mobile telephony, we provide an account of how the microlevel practices of consumers can lead to changes at the field level. We find that, in particular contexts, consumers collectively create and diffuse new practices from their everyday innovative activities. The widespread adoption of these practices then generates responses from more purposeful organized actors who may not always anticipate these innovative practices and their impact on product ontologies, industry recipes, and boundary beliefs (Galvin et al. 2005). If these practices then become widely diffused, enduring, and institutionalized, and if they receive the endorsement of more organized actors so that participation becomes increasingly mandatory, they can lead to field-level change.

In conceptualizing the role of consumers in field-level change, we make two primary contributions. First, by studying the role of consumers in creating and diffusing new practices around a product, we begin to deal with an important field constituent whose role has not been addressed to date despite the fact that it exists in one form or another in a great many organizational fields. This is not, therefore, a special case, but it is instead a generic category of field constituent that has been largely ignored in previous research. Indeed, even recent work on the emergence of new practices continues to focus on a range of organizational actors (Lounsbury and Crumley 2007, Sanders and Tuschke 2007) while neglecting consumers. Furthermore, this effort to include consumers more explicitly parallels similar attempts to integrate the increasingly active and cocreative role of consumers in business into other theoretical areas in management (e.g., Priem 2007).

Second, in contrast to most conventional accounts of change that ascribe change to external "jolts" (e.g., Meyer 1982), endogenous pressures (e.g., Schneiberg 2005), or the purposeful activities of institutional entrepreneurs (e.g., DiMaggio 1988), we add to the limited existing work (e.g., Dorado 2005) on understanding the role of consumers in change by explaining how the collective yet uncoordinated microlevel activities of this unorganized group of actors can result in the establishment of new practices that lead to changes at the field level. As Weick et al. (2005, p. 417) argue, the macro/ micro divide in institutional theory can be reconciled "if we focus on mechanisms that link micro-macro levels of analysis and if we pay as much attention to structuring and conversing as we do to structures and texts." Our study provides some insight into these micro-macro linkages by explaining how microlevel innovations among consumers lead to new practices that catalyze changes at the field level.

We present our argument in four steps. First, we discuss the existing literature on the creation of new practices and change in organizational fields and present our research question. Second, we describe our research methods and summarize the historical development of SMS in the United Kingdom. Third, we present our findings. We conclude with the implications of our findings for theory and practice.

\section{Theorizing Change in Organizational Fields}

In studying the role of consumers in institutional processes, we adopt a field-analytic approach because it provides a "fruitful context for tracing and interpreting the process of change in institutional practices" (Leblebici et al. 1991, p. 333) by bringing into relief the contextboth microlevel processes and macrolevel dynamicsin which the various actors exist and evolve. Indeed, "a field-level approach is especially appropriate during unsettled times such as today" (Davis and Marquis 2005, p. 37), when many formerly distinct industry boundaries are converging, disappearing, or being redefined, such as in banking and in media and communications.

We follow DiMaggio and Powell (1983, pp. 143-148) and define organizational fields as "those organizations that, in the aggregate, constitute a recognized area of institutional life: key suppliers, resource and product consumers, regulatory agencies, and other organizations that produce similar services" (italics added), develop "mutual awareness," and see themselves as part of the same community and "involved in a common enterprise." It is worth noting that consumers are an integral part of this definition of an organizational field. Fields are characterized by sets of institutions, which we define as durable, supraorganizational social arrangements"relatively widely diffused practices, technologies, or 
rules" (Lawrence et al. 2002, p. 282) - that have become entrenched in the field (Leblebici et al. 1991).

Field-level change, then, is a change in the "form, quality, or state over time" of the institutional characteristics of an organizational field (Hargrave and Van de Ven 2006 , p. 866). Writers have identified various ways in which organizational fields can change. These include change in the "ongoing interactions" between actors (Barley and Tolbert 1997), change in sets of institutions (Hargrave and Van de Ven 2006), and change in institutional logics - sets of socially constructed and deeply held assumptions, values, beliefs, and shared interpretive schemes that define appropriate practices, boundaries, and behaviors within fields (Friedland and Alford 1991, Rao et al. 2003). Dacin et al. (2002, p. 50) provide a comprehensive typology of change in organizational fields including "(1) changes in relations among existing organizations, (2) change in boundaries of existing organizations, (3) the emergence of new populations, (4) changes in field boundaries, and (5) changes in governance structures." And, as Reay and Hinings (2009, p. 631) argue, change in fields "is usually associated with a new logic."

Many accounts of change in organizational fields are "actor-centric" (Maguire and Hardy 2008) and privilege purposeful actors such as "institutional entrepreneurs" as sources of change in organizational fields. Studies of the activities and effects of purposeful actors have provided increasingly well-developed theoretical frameworks for understanding this important source of institutional change (Garud et al. 2007). These actors may include firms, the government, professional and trade associations, and special interest groups-any constituent that intentionally influences the field (Scott 2001). Some scholars have argued for the particular importance of purposeful actors who are central and embedded. Greenwood and Suddaby (2006), for example, in their study of the field of accounting, found that it was elite, central organizations that were more likely to come into contact with contradictory field logics, disturb field-level consensus, and create change.

But it is not just central and resourceful actors that make change possible. "Poorly resourced" actors on the peripheries of organizational fields or those from adjacent fields not benefiting from existing institutional arrangements can also precipitate change (e.g., Rao et al. 2000). For example, "disruptive challengers" like Napster were able to undermine the well-entrenched "status quo incumbents" and create space for new practices in the face of stiff opposition-in this case, from powerful traditional networks in the American music industry (Hensmans 2003). Indeed, "process-centric" accounts (Maguire and Hardy 2008), such as those drawing on social movements, highlight the collective, distributed, and contested nature of change and acknowledge the "institutional work" (DiMaggio 1988, Lawrence and
Suddaby 2006) of multiple, diverse, and spatially dispersed organizations (Lounsbury and Crumley 2007) toward creating, maintaining, and disrupting institutions.

Although in the above instances change is the result of the activities of purposeful actors, core or peripheral, as we mentioned above, this need not always be the case. Change may also be the cumulative result of ongoing social interaction among unorganized, nonstrategic, and nonpurposeful actors as they act to solve the problems they face in their daily lives (Dorado 2005, Munir et al. 2007). Such a perspective presents an alternative model of change from the functionality premises that the "design school" (Hargrave and Van de Ven 2006) seems to suggest and one that does not privilege purposeful actors acting strategically to introduce and diffuse novel practices and bring about "top-down" change (Kaufman and Patterson 2005).

\section{The Role of Consumers in Field Change}

From an institutional perspective, consumers are just this sort of unorganized and nonpurposeful field constituent in the sense that they are not jointly engaged in an institutional project. However, in certain contexts, it may be possible that they can, through their ongoing and everyday activities at the micro level, catalyze changes at the field level. Consumers are acknowledged to be an integral part of organizational fields (DiMaggio and Powell 1983), but they generally span multiple organizational fields and are not wedded to any one of the fields they participate in. Their role is therefore potentially important to understanding institutional processes, yet little attention has been devoted to theorizing it.

It is not that institutional theory has altogether ignored consumers who perform key roles as "adopters" of innovative practices (Delbridge and Edwards 2008). A considerable amount of scholarship discusses how innovators of a new product, process, or service seek cognitive legitimacy by embedding innovations in existing understandings to promote the product's uptake by these adopters and gain wider acceptance (Hargadon and Douglas 2001). Munir and Phillips (2005, p. 1673), for example, argue that Kodak was able to gain legitimacy for its innovation (the roll film camera for snapshot photography) by embedding the product in the idea of a popular social institution-the vacation-that entailed "bringing back proof" of the experiences during a vacation. It is worth noting that it was only when consumers were able to identify themselves in various roles such as "tourists" preserving memories of their "vacation" that snapshot photography became widely adopted and led to field-level changes.

However, rather than producers attributing specific activities, responsibilities, and roles to the intended consumers of a product, at times it may be consumers who provide the "scripts" for changes in products and services (Faulkner and Runde 2009). Thus, 
whereas the role of consumers as adopters has been acknowledged, what has received less attention is how consumers actively rework and transform symbolic meanings encoded in products and develop practices aimed generally at enriching personal experience and lifestyles. For instance, consumer groups highly committed to the environmental movement aroused collective enthusiasm for "green" causes among other consumers, producers, and regulators, leading to industry responses such as the development of the hybrid car (Rao 2009).

Our focus here is not simply to understand consumer preferences and innovative behavior, or how firms can leverage innovative consumer groups to improve products and services for organizational ends, but rather to examine how unorganized groups of consumers innovate practices-activity patterns shared by groups of actors that are infused with meaning and provide tools for ordering social life and activity (Lounsbury and Crumley 2007, Schatzki et al. 2001) — around a product or service and, importantly, to explore some of the broader ramifications of this institutional process. In particular, we are interested in how the collective but uncoordinated and often nonpurposeful activities of consumers can converge and lead to new practices that may then result in changes at the field level. Summarized as a research question, how do the uncoordinated activities of consumers as they innovate and diffuse new practices around a product or service lead to change in the organization field?

Moreover, although consumers may be an important source of new practice creation and generate pressure for field-level changes, it is clear that they are not always important catalysts of field-level change. We therefore need to go further and ask what factors make it more likely that consumers will play this role. Are there particular features of the field or broader societal context that make this more likely? Do the nature of the product in question and the kinds of practices consumers develop around it play a role? Existing accounts do not provide explanations of what kinds of contexts enable consumer-led innovation and diffusion processes that lead to field-level change. In summary, what conditions make consumer-led creation and diffusion of practices and subsequent field-level change more likely?

\section{Methods}

This article is based on a seven-year study of how consumers collectively contributed to the institutionalization of the practice of text messaging in the United Kingdom and how this affected the field of mobile telephony. In the tradition of studies such as Leblebici et al. (1991) and Farjoun (2002), we use historical narrative analysis to clarify the event sequences (Greenwood and Suddaby 2006) that occurred as consumers established new practices in the field of mobile telephony. As researchers, we entered the field to explore how change occurred in its natural setting, "attempting to make sense of, or to interpret, phenomena in terms of the meanings people bring to them" (Denzin and Lincoln 2000, p. 3).

The project began in November 2000 and was part of a larger research program focused on developing a longitudinal and processual understanding of change (Locke 2001, Pettigrew 1990) in mobile telephony in the United Kingdom. In this paper, our interest is in explaining the role of consumers in the creation and diffusion of texting as a practice. Because we were interested in gaining a rich understanding of an unfolding institutional process in its real-life context (Yin 1993), we adopted a qualitative research approach.

Our interest was in "theory elaboration" through an in-depth single case study to address conceptual issues that were not transparent in existing theory (Eisenhardt 1989), because a general neglect of consumers in institutional theory has tended to obscure the dynamics of how consumers' activities impact organizational fields. To build more confidence in our findings, and to come up with "holistic and multifaceted explanations of change" (Pettigrew 1990, p. 269), we triangulated across multiple sources of evidence including archival, industry, and consumer interviews, observations, and field-related conferences.

\section{Research Context}

In this study, we analyze the organizational field of mobile telephony-a complex and important field that constituted about $2.3 \%$ of the total UK economy in 2004 (Centre for Economics and Business Research 2004). Following DiMaggio and Powell's (1983, p. 143) definition of an organizational field, mobile telephony forms a clearly "recognized area of institutional life." At the time of the study, the field consisted of mobile network operators, virtual operators, handset manufacturers, suppliers, trade journals, regulatory agencies, industry associations, content providers, standards bodies, other supporting and related organizations, and consumers-business and private-who depended on the system and related technologies to communicate wirelessly. Understandably, in an era of technological and industry convergence, the institutional context was multidimensional, where actors were confronted with opportunities and constraints from both their primary institutional environment as well as from secondary environments (Sanders and Tuschke 2007), such as the related fields of fixed-line telephony, the Internet, and even media and advertising.

In the 1990s, the shared beliefs of actors in this field developed around providing voice-based mobile services as distinct from fixed-line services, and they shared a sense of "being in the same boat" in having a clear understanding of being involved in mobile telephony as a distinct area of activity. Around the year 2000, in the wake of stagnating revenues from voice-based telephony, 
the industry sought new ways to increase the "average revenue per user" (ARPU) by introducing sophisticated data-based mobile services via the new Wireless Application Protocol (WAP) system that enabled mobile telephone users to access the Internet. ${ }^{2}$ Taking cues from rapid growth in Internet data services (Economist 2004), "mobile" Internet was seen by members of the field as a natural extension of mobile telephony that would make the Internet mainstream and widely accessible by eliminating the need for consumers to own laptops and personal computers (PCs).

However, although WAP was intended as the first major mobile data service to provide direct access to Internet content and to take over from voice as the main source of industry growth, it had very limited success. Instead, it was a completely unanticipated service that created a transformation in the industry as consumers adopted SMS despite the fact that it had very limited functionality. ${ }^{3}$ Thus, although the industry had promoted Internet browsing in its quest to make telephony data-centric, it was text-based social communication that diffused ${ }^{4}$ widely and shaped the change in mobile telephony.

Our focus in this study is on text-based communications in the United Kingdom from 1999 to 2008. We chose this time period for several reasons. First, we wanted to examine how consumers innovate and diffuse practices that impact a field. Although consumers did not develop the product that enabled text messaging, they built innovative practices around it that became highly institutionalized over time as the standard solution to their communication needs.

Second, this field was characterized by consumer-led rather than firm-led creation and diffusion of a practice. Although text messaging did not replace conventional "voice" telephony (though it did retard its growth), it became the preferred practice among consumers in many situations where voice telephony was previously the norm.

Third, we wanted to examine a field characterized by changes "compressed in time," providing researchers the "opportunity to document the full sequence of institutional evolution" (Farjoun 2002, p. 853). Text messaging is a relatively recent phenomenon that underwent meteoric growth since it began in 1999.

Finally, we wanted to examine the rise of a practice whose rapid growth was not simply a story of product diffusion driven by falling prices. Unlike the case of voice, where reductions in the cost of the phones and phone services played a major role in increasing usage, SMS is a service "that has grown rapidly without a corresponding decrease in pricing" (Lacohée et al. 2003, p. 206). Although the cost of a single text was generally less than a call, the nature of texting often resulted in protracted conversations over SMS. Thus, in place of a short "voice" call, consumers often exchanged multiple text messages, incurring cumulative bills far in excess of a single call (Taylor and Vincent 2005). Given the rapidly rising volumes of messages, the networks have had little incentive to reduce prices, and the price of SMS has, on average, stayed relatively steady at about $10 \mathrm{p}$ a message during the period of our study.

\section{A New Practice in Mobile Telephony}

SMS was part of the GSM standard for mobile networks introduced in Europe in the early 1990s. At that time, mobile operators viewed SMS much like a pager for sending messages to the mobiles of engineers and technicians working on site and did not envisage it as having much consumer relevance. In fact, they initially did not even set up a billing system for charging consumers for exchanging text messages (Taylor and Vincent 2005). But instead of a simple extension of paging, text messaging represented an important shift in the way people communicated with one another. It signaled a "move from an oral to a visual culture" resulting from a change in the nature of mobile communication from the "spoken word" to the "written message" (Benson 2000, p. 1).

That SMS became a widely diffused and institutionalized practice is evident. In 2007, the 60 million residents of the United Kingdom used 65 million active handsets to send about 55 billion messages, or approximately 150 million text messages a day (Mobile Data Association 2009). This greatly exceeded the number of voice calls made by the same number of consumers as well as the e-mails sent by the approximately 35 million PC users in the United Kingdom. In 2008, over 3 billion SMS users worldwide sent over 3.6 trillion messages, or over 300 billion messages a month, generating revenues of 130 billion dollars (compared with e-mail revenues of 3 billion dollars from about a billion Internet users), and this usage is projected to continue to grow at a rate of $40 \%$ a year (International Telecommunication Union 2009) and account for over $80 \%$ of all data revenues through 2013. In 2008, the leading countries in SMS use were the Philippines (600 messages sent per person per month), Singapore (360), South Korea (300), the United Kingdom (120), the United States (120), China (90), and Japan (30). Particular socioeconomic and technical conditions explain variations in the way text messaging evolved in these countries, and although there were transnational parallels to the phenomenon we examined, these figures also suggest context-specific differences in how texting evolved in different countries.

In the United Kingdom, whereas operator revenues from mobile voice services between 2001 and 2008 remained relatively flat, SMS experienced tremendous growth and by the end of 2008 contributed over $20 \%$ of operator revenues (98\% of all data revenues) and $40 \%-55 \%$ of all mobile operator profits (Office of Communications 2009). The figures for WAP pale in comparison; even by 2005 , it contributed only about 
$2 \%$ of total revenues. More than $75 \%$ of mobile phone subscribers used SMS and less than $10 \%$ used WAP (Mobile Data Association 2009). The average number of text messages exchanged in the United Kingdom rose from 50 million a month (1.7 million a day) in 1999 to 4.5 billion a month (150 million a day) in 2007, totaling about 55 billion texts for the year compared to just 16 million WAP page accesses. As we noted earlier, although SMS was not inexpensive to use once the operators implemented service charges, it nevertheless became the standard and taken-for-granted solution to most mobile communication needs. To give a sense of the order of events in the evolution of text messaging and WAP, we provide a timeline of key events in Table 1. The purpose of the table is to track major milestones, such as consumer adoption and diffusion, new entrants' activities, and industry moves, to illustrate some of the changes occurring at the field level.

\section{Data Collection}

Data were acquired primarily from three sources: archival research, interviews with industry participants and consumers, and attending conferences. Our data collection and analysis efforts occurred over a period of seven years, as shown in Table 2, where we also indicate the type, source, amount, and timing of data collection.

Archival Sources. Using search criterion that included keywords such as consumers, operators, and texting, we consulted a wide variety of publicly available documents on the evolution of SMS, including data available on the Internet, such as consumer SMS portals and websites ${ }^{5}$ dedicated to "texting" communities. These resources are particularly important in this case because text messaging was first adopted by the Internet-savvy teenage community and is essentially a "digital" phenomenon.

Industry Interviews. To enhance the credibility and dependability of our research (Lincoln and Guba 1985) and to further refine and validate interpretations that we developed from archival data, we carried out 30 semistructured interviews with network operators, manufacturers, and intermediaries involved in the field of mobile telephony. We identified and selected appropriate respondents using "purposive sampling" (Patton 2002) based on their role in the rise of SMS. This type of sampling permitted us to choose a wide range of people whose perspectives might be complementary, conflicting, or even contradictory. The interviews took place between 2001 and 2005 and allowed us to compare initial responses at the beginning of the rise of text messaging with those after its effects had played out. For instance, in 2001, some in the industry described text messaging as "primitive" and "low-tech," but in 2005, after its widespread diffusion, most acknowledged it to be the "ugly duckling" of the Global System for Mobile Communications (GSM) that turned out to be the biggest consumer-driven "killer application" for second-generation mobile telephony. The interviews ranged from 60 to 90 minutes in duration and were taped and transcribed. We also sent early drafts of this paper to key informants to verify our findings.

Consumer Interviews Observation and Surveys. To better understand the conditions under which consumer practices can bring about changes in a field, we interviewed consumers who had a "lived" experience of the phenomenon (Patton 2002). Using a semiformal interview guide (Kvale 1996), we tried to maintain a natural flow of events and conversations in the setting. Our respondents included 53 commuters on trains between London and Cambridge and 54 students from educational institutions in the London area. Our criterion for selecting respondents was to cover as wide a range of customer demographic groups as possible. We also conducted observations (and occasionally informal discussions) of consumers in various settings such as trains, malls, and cafés to get a firsthand view of the SMS phenomenon. This provided us with more "situated" detail about how they used texting in their day-to-day activities. We also drew on the results of published largescale interview-based studies to enable us to cross-check that the ideas gleaned from our respondents were not idiosyncratic.

Conferences. Finally, we participated in several conferences on a variety of aspects of mobile telephony. These conferences were "field reconfiguring events" (Lampel et al. 2005) attended by key decision makers representing various stakeholders in the organizational field. Through observations, informal discussions, and exchanges with knowledgeable informants who viewed the phenomenon from diverse perspectives, we gained valuable insights into the evolving field.

\section{Data Analysis}

Given the relative paucity of empirical work exploring how consumer practices catalyze change in organizational fields, we pursued an inductive theory elaboration approach. As is typical with interpretive research based on qualitative data, throughout our analyses, we moved iteratively between different data sources and between the data and the concepts generated (Locke 2001). We analyzed the data in two stages. First, to trace the evolution of the field from the original inception of SMS in the 1990s to mid-2008, we sorted the data to construct a database of salient events in chronological order, the sources from which we had identified these events, and our interpretations (Miles and Huberman 1994).

After sorting the data, we carried out a systematic reading of all articles, transcripts, conversations, and notes, totaling some 2,700 pages. We then created a document summary form for all documents that indexed key data about the document and tracked key issues, ideas, questions, and concepts that emerged from each document. Similarly, for each interview, we developed a 
Table 1 Timeline of SMS- and WAP-Related Field-Level Developments in Mobile Telephony

Date SMS- and WAP-related developments in mobile industry

1985 SMS considered as a possible data-based service for the new voice system GSM.

1987 Technical standard created by a GSM body called IDEG (Implementation of Data and Telematic Services Experts Group) as a service for telecom engineers to exchange technical messages.

1992 The first commercial text message sent by an engineer in December over the Vodafone network.

1994 Mobile Data Association (MDA) established — a key forum for the international mobile data community to increase awareness of mobile (Internet) data among users and companies.

SMS launched commercially but without promotion or fanfare; still seen as a medium for internal technical and business use.

Revenues from voice-based telephony peak off, industry looks for new ways to increase ARPU. An industry consortium called the WAP Forum launched WAP as global standard for bringing Internet services to mobile devices. WAP uses packet-based technology for data transmission (also employed for data transmission over Internet) rather than circuit-switched technology used for voice services.

Interconnect established between UK Operators O2, Orange, Vodafone, and T-Mobile to improve voice-based networks, which also allowed people to exchange text messages across different networks.

Flexible pay-as-you-go payment plan launched to increase mobile subscriptions that allowed consumers, especially teenagers, to become mobile customers without qualifying for pay-monthly contracts. Teenagers began experimenting with text messaging, and the first recorded monthly text message total was 5.4 million in April.

Operators introduce billing system for charging texting consumers; however, industry continues to focus on WAP.

The word "texting" becomes part of major dictionaries. Teenagers develop SMS jargon consisting of symbols and abbreviated words and expressions, some of which appear in the Oxford dictionary.

The website Text.it launched in July and provides the definitive text messaging information source for consumers and the mobile industry community.

WAP is launched and heavily promoted by the industry as "mobile Internet" (put Internet "in the pocket") but consumers show little interest.

2001 Text messaging diffuses across other demographic groups. Number of messages sent in the United Kingdom in the month of August reaches over 1 billion; use still mostly for social interactions.

2002 In December, 1 billion messages per day were exchanged globally and 50 million a day in the United Kingdom.

MDA reports the total numbers of Mobile Internet WAP page impressions (PIs) or user request received by server to access a file. Eleven million PIs per day were accessed, but this did not reflect customer penetration because a single user could access multiple Pls during a single WAP "session."

Increasing usage of SMS attracts new entrants, such as ringtone companies that promote new commercial uses for SMS.

Most manufacturers incorporate predictive text technology to facilitate typing on small telephone keypads. Vendors equip more expensive models with full QWERTY keyboards.

2003 SMS continues exponential growth and on New Year's Day 2003, the number of text messages sent in one day topped 100 million. The number of WAP PIs is about 15 million.

Incumbent operators actively promote SMS use and offer attractive SMS packages.

As new uses for texting gain ground, incumbents devise new business models to share texting revenues with "content providers" such as a publisher, TV broadcaster, or advertiser.

2004 More new entrants commercially leverage SMS earning revenues from texting audiences such as TV shows such as Pop Idol. A similar show in the United States, American Idol, causes SMS usage to substantially increase in the United States as well.

The government takes note of this increasingly influential practice. UK Prime Minister uses text messaging to answer questions by text message from members of the public. Governments communicate with the public via SMS to communicate national alerts and other notifications.

2005 To give a clearer picture of how many people access the service each month, MDA revises method of counting by reporting mobile Internet user figures based on unique users accessing the internet on a mobile device at least once in the reporting month. Previously it issued figures relating to the number of WAP page impressions viewed. Twelve million consumer access WAP pages at least once a month compared to 60 million consumers who exchanged text messages at least once a day!

Industry enjoys huge profits from SMS-90\% profit margins as SMS becomes the predominant source of data revenues, constituting $85 \%-90 \%$ of all mobile data revenues.

Improving technologies and better phone models cause increase in WAP usage, but usage is way below SMS despite improvements in service. Annual SMS messages total 32 billion.

Incumbent operators launch new promotional campaigns such as Vodafone's "Joy of Text" to encourage even more use of SMS Practice becomes widely diffused among businesses, with $60 \%$ of firms using it on a daily basis.

2006 SMS becomes truly a mass medium of communication; $80 \%$ of overall mobile phone subscribers and $95 \%$ of 16 - to 24 -year-olds used text messaging regularly, whereas less than $14 \%$ occasionally used WAP service in the United Kingdom.

SMS use continues to grow with over 40 billion messages sent throughout the United Kingdom during 2006, with an average of 100 million messages being sent per day and 165 million messages sent on New Years' Day. Almost $85 \%$ of use still person-to-person social interactions but other uses continue to grow. WAP usage improves but remains marginal both in terms of use and revenues. About 13 million consumers access WAP pages at least once a month, whereas over 60 million consumers send over 3 billion message a month. SMS constitutes almost $90 \%$ of data revenues, and WAP-related services about $10 \%$. Analysts predict continued growth in SMS despite such high levels of penetration and use.

2007 SMS use continues to grow with over 50 billion messages sent throughout the United Kingdom during 2007, with an average of 120 million messages being sent per day.

2008 SMS growth continues, and 55 billion messages sent throughout the United Kingdom during 2008, with an average of 130 million messages being sent per day.

In United States, where SMS was comparatively a slow starter but with increasing popularity of texting fuelled by television shows such as American Idol (highest rating for any show) and a spike in use of texting to connect with voters during the Obama presidential campaign, usage at par with the European average.

Worldwide, over 3 billion SMS users sent over 3.6 trillion messages or over 300 billion messages a month, generating revenues of 130 billion dollars (compared with 3 billion dollars of e-mail revenues from about a billion Internet users); this usage is projected to continue grow at $40 \%$ a year (International Telecommunication Union 2009) and account for over $80 \%$ of all data revenues through 2013 
Table 2 Data Summary

\begin{tabular}{|c|c|c|c|c|}
\hline Type of data & Detail of source & Amount of data & Time of collection & Analysis of data \\
\hline $\begin{array}{l}\text { Archival_-journal, } \\
\text { newspaper, and } \\
\text { special reports } \\
\text { and websites }\end{array}$ & $\begin{array}{l}\text { The Financial Times, the Guardian, } \\
\text { the Economist, Wireless Review, } \\
\text { and Wireless News; dedicated } \\
\text { SMS websites; reports by the } \\
\text { Office of Communications } \\
\text { (Ofcom), the Mobile Data } \\
\text { Association, the International } \\
\text { Telecommunication Union, the } \\
\text { Digital World Research Centre, } \\
\text { the Social Issues Research } \\
\text { Center, Carphone Warehouse, } \\
\text { and think tanks such as Demos. }\end{array}$ & $\begin{array}{l}290 \text { articles spanning } \\
1,844 \text { pages }\end{array}$ & 2000-2008 & $\begin{array}{l}\text { Chronologically analyzed to } \\
\text { examine how over time texting } \\
\text { became a widely diffused } \\
\text { practice and also to document } \\
\text { changes in an organizational } \\
\text { field across several } \\
\text { theoretically specified } \\
\text { dimensions; added contextual } \\
\text { depth to understanding overall } \\
\text { change activities and product } \\
\text { features. }\end{array}$ \\
\hline $\begin{array}{l}\text { Primary interviews } \\
\text { with consumers } \\
\text { including field } \\
\text { notes from } \\
\text { observation }\end{array}$ & $\begin{array}{l}107 \text { subjects - } 53 \text { commuters on } \\
\text { trains between London and } \\
\text { Cambridge, and } 54 \text { students } \\
\text { from educational institutions in } \\
\text { the London area. }\end{array}$ & $\begin{array}{l}107 \text { respondents with } \\
225 \text { pages of text }\end{array}$ & $\begin{array}{l}2000,2004 \text {, and } \\
2005\end{array}$ & $\begin{array}{l}\text { Transcribed interviews coded } \\
\text { and analyzed for first- and } \\
\text { second-order constructs. }\end{array}$ \\
\hline $\begin{array}{l}\text { Interviews with } \\
\text { organizational } \\
\text { respondents }\end{array}$ & $\begin{array}{l}\text { Interviews with managers from } \\
\text { mobile operators (e.g., Vodafone } \\
\text { and Orange), virtual operators } \\
\text { (e.g., One.Tel), manufacturers } \\
\text { (e.g., Nokia and Sony-Ericsson), } \\
\text { content providers (e.g., Walt } \\
\text { Disney Group), intermediaries } \\
\text { (e.g., HSBC Bank), and various } \\
\text { industry experts. }\end{array}$ & $\begin{array}{l}30 \text { interviews with } 245 \\
\text { pages of text }\end{array}$ & 2000-2005 & $\begin{array}{l}\text { Transcribed interviews coded for } \\
\text { concept development; } \\
\text { enhanced validation, } \\
\text { credibility, and dependability } \\
\text { of interpretations that we } \\
\text { developed from archival and } \\
\text { consumer data. }\end{array}$ \\
\hline $\begin{array}{l}\text { Archival interviews } \\
\text { on consumers }\end{array}$ & $\begin{array}{l}\text { Studies by Plant (2000) and Fox } \\
\text { (2001) involving 4,000 and } \\
5,000 \text { consumers, respectively; } \\
\text { ethnographic studies on mobile } \\
\text { usage (Crabtree et al. 2003) } \\
\text { and reports by think tanks on } \\
\text { the social effects of mobile } \\
\text { technologies (Harkins 2003); } \\
\text { Mobinet survey (Menon et al. } \\
\text { 2005) on mobile data, based on } \\
\text { five-year study of 30,000 } \\
\text { consumers in } 21 \text { countries. }\end{array}$ & 295 pages & 2000-2008 & $\begin{array}{l}\text { Analyzed to attain wider and less } \\
\text { idiosyncratic consumer } \\
\text { perspective on the practice of } \\
\text { texting. }\end{array}$ \\
\hline Observations & $\begin{array}{l}\text { Studying and observing situated } \\
\text { use of text messaging in cafés, } \\
\text { bars, trains, malls, etc. }\end{array}$ & 84 pages & 2001 and 2004 & $\begin{array}{l}\text { Meeting notes transcribed and } \\
\text { reviewed to understand } \\
\text { consumer practices. }\end{array}$ \\
\hline $\begin{array}{l}\text { Conferences and } \\
\text { workshops }\end{array}$ & $\begin{array}{l}\text { GSM and 3GSM conferences } \\
\text { 2002-2004; the Financial Times } \\
\text { World Mobile Communications } \\
\text { Conference 2002, 2004, 2005, } \\
\text { and 2006; and First Mobile } \\
\text { Marketing Congress, "From SMS } \\
\text { to Mobile TV," 2006. }\end{array}$ & 45 pages of notes & 2002-2006 & $\begin{array}{l}\text { Notes from presentations and } \\
\text { informal exchanges with } \\
\text { speakers and participants } \\
\text { reviewed for a more informed } \\
\text { industry perspective; } \\
\text { comparison of texts, e.g., } \\
\text { mmO2's CEO's speeches in } \\
\text { 2002, 2004, and 2006. }\end{array}$ \\
\hline Total & & 2,940 pages & 2000-2008 & $\begin{array}{l}\text { Repeatedly examined proposed } \\
\text { relationships against data from } \\
\text { which they were derived; } \\
\text { iterative analysis of literature } \\
\text { and data led to theoretical } \\
\text { account of the creation and } \\
\text { diffusion of novel practices } \\
\text { and how they catalyzed } \\
\text { institutional change. }\end{array}$ \\
\hline
\end{tabular}


memorandum detailing our impressions concerning what and who triggered changes in the field. We continued this process of reviewing documents and cataloging key issues in the document summary forms until it appeared that we had reached theoretical saturation (Glaser and Strauss 1967).

At this point, we moved on to the second stage to answer our research question. We focused on the role of consumer practices in catalyzing change in organizational fields. To anchor our investigation, we began by asking, how did new practices emerge and diffuse? Which types of consumers introduced them? We began by coding the document summary forms using the "cycle of change in institutional practices" that begins with the innovative activities of actors at the fringes of an organizational field (Leblebici et al. 1991, p. 357). We used our database of salient events to assign indicative temporal markers during this cycle's evolution. To study the interplay between practices and field-level changes, we coded the document summary forms using the types of change identified by Dacin et al. (2002).

Next, we collected together coded text units that made a similar point and worked iteratively among our coded text units. We then assigned each group a set of labels that were mutually exclusive and exhaustive (see Miles and Huberman 1994). These categories formed our firstorder concepts. Examples of the categories that emerged include actors such as "content providers" as well as "texting language." Types of change included "entry of new types of actors" and "new uses for mobile phones."

To understand the underlying patterns in our qualitative data (Kvale 1996), we refined the first-order concepts and iterated between the emerging categories and the literature on new practice emergence to develop more parsimonious, nonoverlapping, second-order concepts (Miles and Huberman 1994). We assigned theoretical labels to the resulting concepts based on a more general description that subsumed the first-order concepts (e.g., "consumer practices"). This provided us with an increasingly accurate description of what happens during the initial stages of new practice creation and how practices create pressure for change when there are no clearly identified institutional entrepreneurs.

To examine the conditions that make it more likely that consumers will create and diffuse a new practice, we repeated the process to capture the conditions encouraging the consumer-led creation of a practice. Finally, our engagement in the larger research program around mobile telephony in the United Kingdom gave us a sense of the relationship between the practices we examined and the broader macrocultural environment. Throughout the process, we worked to increase the dependability and trustworthiness of the analysis by working systematically and iteratively between the data and the literature, by rechecking our assumptions, and by considering and eliminating alternative explanations (Lincoln and Guba 1985).

\section{Consumer Practices and \\ Field-Level Change}

We distinguish three phases in this process of field-level change, each characterized by key events and developments that took place during that phase. The first phase concerns how consumers innovated and diffused the practice, whereas the second and third phases describe the responses of organized actors to this consumer-driven innovation. It is important to note that the dates indicated for the transitions do not reflect exact moments of change during the very rapid rise of text messaging. Rather, they represent partially overlapping phases in the evolution of this consumer-led practice that came to impact the field in important ways. The complete three-phase process is shown in Figure 1 and is explained below.

\section{Phase 1: Consumers Create and Diffuse a New Practice (Circa 1998-2001)}

As we mentioned above, SMS made a rather inauspicious beginning around 1992 as a "telenote service" intended for internal messaging among engineers and technicians (Giussani 2001). Operators saw little commercial potential in a service viewed as the cellular equivalent of paging and were initially reluctant to throw their weight behind a "low-tech" system with a message limit of 160 characters. But despite these concerns, SMS was included in the GSM standard and was a feature on GSM mobile phones. As the use of these phones became widespread in the 1990s, SMS as an option was already available, familiar, and widely disseminated.

However, although SMS was not meant to be a service for widespread adoption, consumers rapidly appropriated the SMS platform despite its negative "affordances" or technical features (Hutchby 2001). In this case, the experience of typing out text messages limited to 160 characters on small-sized monochrome phone screens using tiny 12-key, non-QWERTY keyboards, coupled with lack of service reliability, did not appear to be particularly user-friendly. Furthermore, composing messages on mobile phone keyboards based on the standard keypad layout was cumbersome and time consuming. Because several characters are associated with each key on the keyboard, numerous key presses were required to enter one character, and writing two characters from the same key consecutively required a pause in the procedure (Taylor and Vincent 2005). Finally, although it was cheaper to text (about 10p per text) than to call (about $20 \mathrm{p}$ a minute), group social pressures to reply to every text message led to protracted conversations over SMS, thereby incurring bills in excess of what a simple call may have entailed (Taylor and Harper 2003). In short, SMS was decidedly low-tech, user-unfriendly, and often expensive in practice.

Yet consumers appropriated the SMS platform and began to increasingly engage in texting rather than calling. With texting, consumers recreated the brief, frequent, and spontaneous connections with members of the 
Figure 1 Process of Change in Mobile Telephony Catalyzed by Consumers

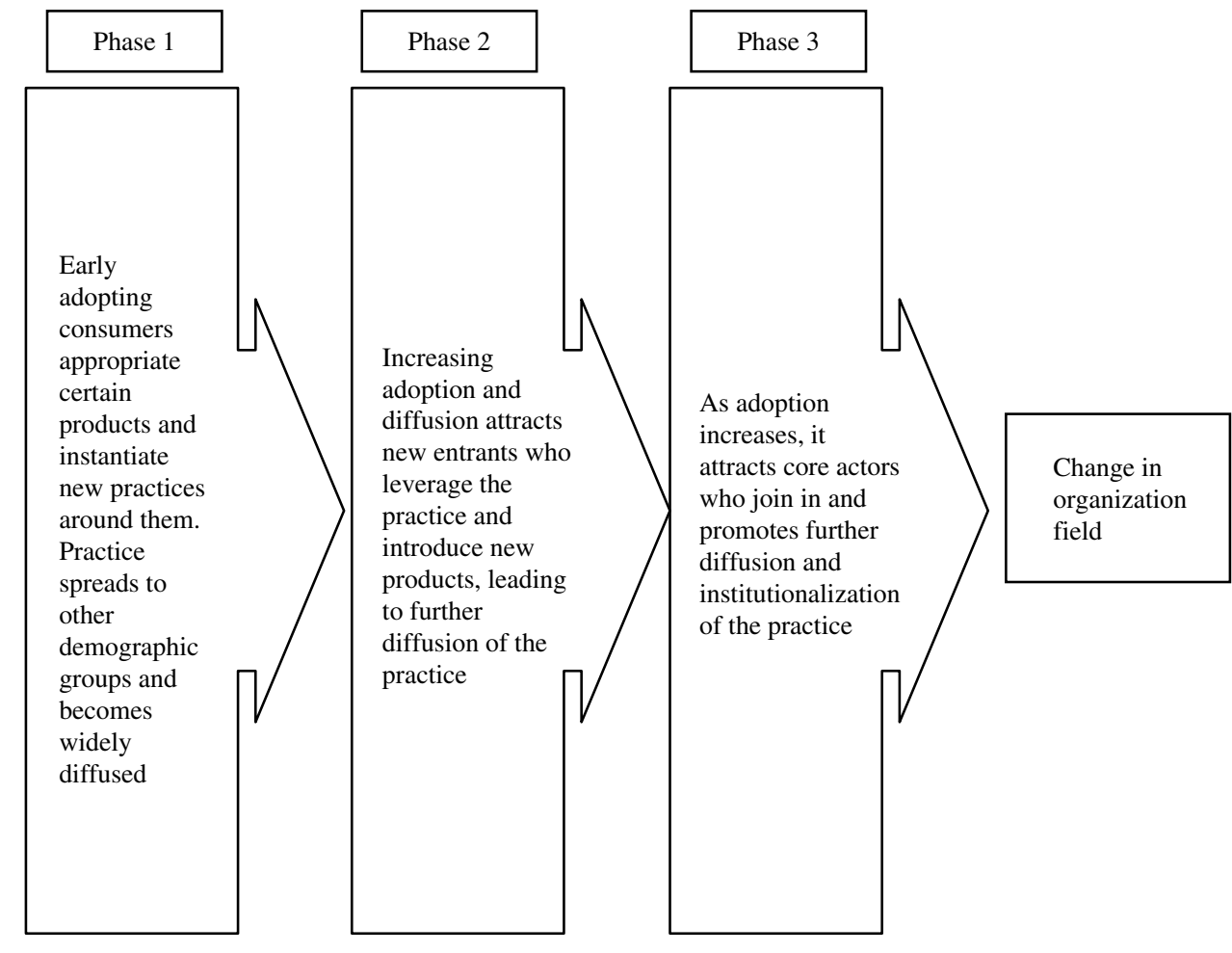

social network reminiscent of "village-green" conversations among preindustrial communities and that functioned to maintain and augment social bonds (Fox 2001). Texting provides the brief messages for which there is a huge demand but which do not merit all the rituals attached to a telephone call. Indeed, the predominant text message at the time of the study was "I was thinking of you," rather than more complex and longer messages.

These early adopters, primarily teenagers, made use of several "technical" features of the service, leading rapidly to high levels of use following a trial. First, given that almost everyone had an SMS-capable phone, there was little cost involved in sending one's first text. Second, text messages were durable in the sense that they remain after an exchange unless they are deleted. This allows people to save and reread messages as needed. Third, the asynchronous nature of text messages allows people who receive a message to choose when to read the message, the timing of the reply, and time for composition, editing, and reflection. Users could thus avoid "accidentally" saying the wrong thing, which is a frequent concern in a voice conversation. Fourth, texting is silent, discrete, and unobtrusive, allowing people to carry out private conversations in public. For instance, one of our interviewees stated that they prefer texting rather than calling their friends and partners when in the office, especially in an open-plan office, so that when they "want to say something in private, the whole office doesn't have to know" (27-year-old office manager). Finally, text messaging was adaptable in the sense that it could be used in a variety of ways in different contexts. This flexibility made it possible to integrate texting into numerous aspects of the everyday routines of consumers, as reflected in the following quote:

I never leave home without my mobile and I always read my texts right away. I use it the way I like, to flirt, stay in touch with family, friends, business contacts... share jokes and special moments... send greetings, stories, and even to see updates on my bills or special offers by companies I have allowed. (42-year-old bank employee)

In turn, the emergent practice of texting began to create new patterns of social exchange alongside the dominant practice of voice-based mobile telephony. As users endeavored to say as much as possible within the 160-character limit, they developed "texting language" as a form of collective identity for situating the self in particular social groups or subcultures that have been referred to as the "thumb generation" and "Generation Txt" (Plant 2000). Several of our respondents noted that text messaging allowed very personalized dialogue that often contained shared group references and meanings and helped foster and reinforce a sense of belongingness. By bypassing obtrusive phone calls and freeing themselves of expensive bills from mobile companies (text messages could initially be exchanged for free), young consumers found a way of "reversing power differentials" through "manipulating parental incompetence" and sending coded, indecipherable text messages (Baron et al. 2006, p. 129). The emancipative aspect 
of the practice thus allowed youth to maintain privacy and develop a sense of collective identity in organizing their everyday lives and maintaining social relationships at home, in school, or other urban spaces, autonomously and beyond adult control and surveillance.

The experimentative early adopters appropriated the product for both technical and social reasons, embedded it in their social activities, and infused it with meaning to establish a new practice. Once this group had adopted the practice, it rapidly spread to other demographic groups. The mechanisms included, among other things, word of mouth - a source often seen to be more authentic than industry-sponsored sources (e.g., Stern 1994). As we heard repeatedly in our interviews, the rapid diffusion was largely through personal informal social groups - coworkers, friends, and family. In many cases, SMS was introduced to adults through relationship with their children. These adults would then use SMS to communicate with other adults, as the practice rapidly spread. A 41-year-old mother noted,

I asked my son, how do you write your messages so quickly?... So he showed me this thing called predictive text. I said, "that's pretty neat"... . It took a while, but now I just can't live without it.

Other social drivers that contributed to further adoption and diffusion of the practice included the pressure to reciprocate only through text. When an individual receives a text message, he or she is expected to text and not call back. Also, given that in many cases the use of SMS was observable, an important factor in diffusion was the consumers' desire to use the practice as a way of indicating social popularity. A respondent noted,

This is the joy of the text message. Unlike a phone call, it allows you to look sociable and sought after when all by yourself in public places, even if it is only your mum asking you what you want for dinner that evening.

\section{(27-year-old female office worker)}

In summary, in Phase 1, the practice diffused from early adopters to a wider group of consumers through various forms of social pressure and became part of the lived social experience of a broader group of consumers. Consumers created and diffused the practice of texting almost behind the back of the industry that had focused on bringing about a different kind of change and that, at least initially, had shown little interest in texting. Indeed, there was no "moment of epiphany" at mobile telephony firms when they suddenly embraced this consumer innovation. Yet, over time, there was a marked shift in industry beliefs in light of the undeniable rise in the use of texting and the lack of consumer interest in WAP. Given the rapid rise of this new practice, organized actors had to interpret, make sense of, and respond to consumers' behaviors. We describe their responses in Phases 2 and 3.

\section{Phase 2: New Field Entrants Introduce New Products and Services (Circa 2001-2003)}

As the novel communication "convention" introduced by consumers was adopted by organized actors, it began to change the institutional order by changing the nature of transactions in not only the field concerned but also in adjacent fields like media and communications. No longer the sole preserve of consumer groups, texting began to be increasingly adopted by organizations. Yet, at least initially, so attached were industry incumbents to a future dominated by WAP (mobile Internet) that it was new entrants who first developed major innovations around the practice of texting. It was only later that incumbents joined in with innovations of their own.

As consumer practices unsettled the field, it created opportunities for new entrants to enter mobile telephony and benefit by creating new services, products, and technologies. Compared with the incumbents, these fringe players were less connected, less embedded, and less committed to existing field arrangements and were quicker to innovate in more radical ways (cf. Leblebici et al. 1991). These innovations generated new textingrelated field practices. For example, the rapidly increasing use of texting among consumers allowed the entry of nontelephony firms that specialized in ringtonesdigitally encoded pieces of music downloadable through text messages that could be used to replace the standard ring on a consumer's mobile phone. This service allowed consumers to personalize their mobile phones and communicate socially relevant meaning in their social worlds (Haig 2002). Ringtone firms took advantage of the widespread diffusion of texting and developed a system where consumers could order a ringtone by sending a text message, which these firms would then deliver through a return text message. Ringtones rapidly became very popular, exceeding the value of compact disc sales in the United Kingdom; sales reached almost $10 \%$ of the global music market in 2004 (Gopinath 2005). Because ordering and receiving ringtones required the use of text messaging, it further fueled the use of texting.

Similarly, advertisers and media organizations leveraged texting to enable innovations in advertising and promotion. In many instances, permission-based marketing supplanted telemarketing as consumers elected to receive and respond directly to the advertising messages they received through SMS. Most of the consumers we interviewed noted that they were far more receptive to messages received through SMS than those through e-mail:

You get so much crap spam e-mail; it's just a pain to weed through. It means that many people often don't respond to e-mails unless they have to. Text messages carry a natural sense of urgency.

(33-year-old manager on train)

This was confirmed in other studies that showed SMS to be a highly receptive marketing medium for advertisers, with over $90 \%$ of promotional texts read by mobile 
phone users, compared with $60 \%$ of e-mail and less than $10 \%$ of direct mail (Haig 2002). And regarding response times, whereas $84 \%$ of SMS users expect a response in five minutes, less than half of e-mail users expect a response within 24 hours (Ahonen 2009). One reason why consumers found SMS more acceptable than WAP, even for receiving broadcasted messages, was that the word limit on these messages created an "equalizing" effect, and all messages-whether marketing promotions or personal-looked the same. As a result, consumers found marketing pitches to be "fairer" and less invasive (Haig 2002). An industry expert noted, "ubiquity of content does not necessarily create relevance" and instead may turn off consumers through information overload, unsolicited intrusions, and sales pitches as often seen in the realm of the Internet.

Finally, we coded for industry convergence; independent production companies in television innovated by launching texting-based premium rate services. These services contributed not only to promoting the use of texting but also to revitalizing broadcast television by accommodating consumer participation and shifting the medium from one-way broadcast communication toward two-way interactivity (Goggin and Spurgeon 2007). Consumers sending premium-rate text messages to vote for their preferred contestants in shows such as Pop Idol not only increased ratings but also provided accurate indications of a show's popularity. In this marriage of mobile texting and television, consumers were no longer a collective audience but rather a composite of individual SMS users, marking the "disappearance of the audience" and the emergence of the "user" (Marshall 2004, pp. 13-24). The convergence also spawned new roles such as the emergence of the "text jockey" responsible for moderating viewer interactions.

In summary, in Phase 2 the activities of these nontraditional new actors led to change in not just the primary organizational field of mobile telephony but also in other fields such as television. Although these actors did not become the new dominant force, they identified and acted on the new opportunity provided by consumers that created further pressure for change before core actors were willing or able to change their central strategies.

\section{Phase 3: Core Actors Join and Field Changes Accelerate (2003 Onwards)}

It took some time before core industry actors began promoting the use of texting. Because texting had brewed in the marginal, low-end teenage community (Taylor and Vincent 2005), mobile operators did not initially anticipate that these prepaid users, barely on their radar, would innovate around a largely disregarded service. At first, the innovation focus in voice services was on features such as caller line identification, and, as we mentioned above, in data services, the industry had converged around promoting WAP. Indeed, although the capability to text had been built into every mobile phone since the late $1980 \mathrm{~s}$, it only took off at the turn of the millennium after lying dormant for well over a decade. The industry had not foreseen widespread consumer use of this application, and until late 1998, they did not enable interconnect services, or the ability to exchange messages between subscribers on different mobile networks. Furthermore, mobile operators had also been slow to set up charging systems, especially for prepaid subscribers, that inadvertently led to free initial usage of the service.

Throughout the period of the early rise of texting, there were few industry initiatives to promote the practice. "Focusing on SMS would have diverted resources from the much more promising WAP," in the words of one mobile operator's innovation manager. The dominant belief at the time was that the GSM standard was meant exclusively for voice services, and interference from texting would "overburden the already clogged voice networks" not optimized for messaging. This was seen to not only harm the business of voice (texting was shown to be a substitute for voice) but also undermine the projected transition to WAP, which was seen as clearly distinct from the voice business. Not surprisingly, the vast majority of the industry presentations we attended at major mobile telephony conferences and the analyst reports we analyzed during the period were almost silent on texting.

Yet, with increasing adoption, the phenomenon began to draw the attention of mobile firms and analysts alike, and gradually new understandings and shifts in behaviors emerged at the field level. A key report from Gartner (2006) declared SMS to be the single most important source of new industry growth. A respondent noted, "The industry had relied on simplistic determinism, relying on the tried and tested technology-focused model of 'if we build it they will buy it.' The growing popularity of texting was a wakeup call for all of us." Similarly, the vice president for mobile software at Nokia noted, "The industry has not been looking at the user. It's been looking at its own navel" (Baker and Clifford 2002). Mobile firms had been very eager to promote "superior" products like WAP. However, the dotcom crash at the end of the 1990s severely dented confidence in new technologies, and they found it increasingly difficult to make further resource commitments when people were still using mobile phones predominantly for social communication (Ansari and Garud 2009). The increasing legitimacy of the new practices eventually reoriented core field actors-incumbent operators and manufacturersaway from WAP as they were pressed into action to promote texting. Not wanting to miss the fast-growing bandwagon around SMS, they began to innovate to commercially leverage the new practice in mobile telephony.

Having invested almost nothing in generating the SMS market, incumbent mobile operators had in fact benefited 
from the unanticipated windfall from the innovations of consumers and new entrants. However, they had missed out on several opportunities to pioneer texting-related innovations. Yet, as controllers of the mobile platform, they were disrupted but not displaced by these innovations. Indeed, once the practice became widely accepted, incumbents responded with innovations of their own in price and packaging, as well as software and hardware changes, to adapt to the growing use of texting.

One software innovation introduced by mobile firms to overcome the 160-character limit was providing consumers the ability to "concatenate" messages or string together two or more messages that could then be read as one. Similarly, phone manufacturers such as Nokia introduced innovative form factors to ease message composition, such as providing phones with more keys and "predictive" text-entry systems that allowed characters to be inputted using a single key press rather than the laborious multitap method (Taylor and Vincent 2005). The system employed a dictionary that could "predict" the most likely word a user was trying to type and thus save time in composing a message.

With the entry of new players in the field, mobile firms also had to rethink their business models to share texting revenues with content providers such as banks, publishers, television broadcasters, and advertisers. As one operator put it, "When we realized there was money to be made [from SMS] we did something about it" (director of strategy, UK mobile operator). Several operators came up with price and packaging responses and innovative ways to promote the use of text messaging. For example, Vodafone UK's 2005 campaign, "The joy of text," encouraged people to join the "textual revolution" in an explicit reference to early adopting teenagers who had provided the initial impetus for adoption (Carphone Warehouse 2006).

In summary, in Phase 3, the incumbent firms that had initially ignored, if not actively resisted, the rapid growth of the practice recognized the sheer momentum generated by consumers and new entrants. Incumbent firms took advantage of attractive business opportunities that had opened up to jump in and devise new business models and commercial applications around this new practice. With the support from core actors, the practice of texting became firmly established. Phase 3 was the ultimate step in the process through which the consumer-led practice enrolled more central field participants and catalyzed field-level changes.

\section{Summary of the Process of Field Change}

To sum up our argument, consumers by themselves were not sufficiently resourced or organized to significantly impact the field on their own. Yet, at the micro level, consumers generated and disseminated innovative practices around an available product, and the collective influence of these practices opened up new opportunities for organized actors. The field then changed as firms at the periphery, and eventually the core, responded to this new opportunity, stepping in to provide further impetus for change. We found evidence for four types of fieldlevel change (Dacin et al. 2002). Table 3 depicts some of the major changes in the field.

First, it resulted in a change in organizational boundaries; operators in particular found themselves involved in a range of new activities such as the provision of textbased voting systems for television programs in collaboration with television broadcasters. Second, it led to the birth of new organizational populations in mobile telephony that specialized in various types of text-based data services, such as ringtone companies and mobile gaming companies. Third, there was a shift in field boundaries, caused by changes in technical interdependencies. For example, the use of text messaging in the home delivery of various health services (such as dosage instructions for diabetic patients) resulted in the inclusion of certain health service providers in the field of mobile telephony (Sarin 2006). Finally, a new contending logic of mobile telephony developed as the field moved from a logic of voice to a logic of text.

This final point deserves further elaboration. Mobile telephony, like its predecessor fixed-line telephony, was traditionally centered on the logic of voice and was characterized by synchronous or real-time conversations, a lack of privacy in public situations, nonverbal cues such as the tone of voice, and usually no trace of the conversation remaining after the completion of the call. Texting, on the other hand, is a new communication convention characterized by asynchronous conversations, private exchanges, no nonverbal clues, and written evidence of the conversation remaining after the exchange. Texting thus changed the meaning of telephony and the social rules, beliefs, and assumptions surrounding the practice: a change comparable to the transition in the field of radio from telegraphy, a pointto-point communication medium, to broadcasting, a oneto-many communication medium (Leblebici et al. 1991).

This change enabled practices that were not possible with voice telephony and that were not anticipated by an industry committed to untethering the Internet and turning mobile telephony into an "Internet everywhere" experience. For instance, texting allowed hyperconnectivity-connectivity in more contexts and with more people. Whereas it was, and still is, considered by many to be unacceptable and intrusive for people to call someone on their personal mobile phone unless they have been invited to, it became acceptable to text them and for organizations to send texting alerts, reminders, and offers to their customers. At the same time, people did not widely adopt surfing the Internet or making online purchases through their mobile phones (m-commerce) - practices the industry had aggressively promoted through WAP. Consumers thus shaped the 
Table 3 Examples of Texting-Induced Changes in the Field of Mobile Communications

\begin{tabular}{|c|c|c|c|}
\hline $\begin{array}{l}\text { Change in organizational } \\
\text { boundaries }\end{array}$ & $\begin{array}{l}\text { Emergence of new } \\
\text { organizational } \\
\text { populations }\end{array}$ & $\begin{array}{c}\text { Change in } \\
\text { boundaries of } \\
\text { organizational field }\end{array}$ & $\begin{array}{l}\text { Change in core } \\
\text { practices of consumers } \\
\text { and business users }\end{array}$ \\
\hline $\begin{array}{l}\text { Core organizations (mobile firms) } \\
\text { entering new domains of } \\
\text { activities to provide texting } \\
\text { services on voice networks. }\end{array}$ & $\begin{array}{l}\text { Birth of new actors that } \\
\text { specialize in text-based } \\
\text { services. }\end{array}$ & $\begin{array}{l}\text { Change in technical } \\
\text { interdependencies and } \\
\text { identities of various field } \\
\text { constituents. }\end{array}$ & $\begin{array}{l}\text { Change in core practices around } \\
\text { mobile telephony from simply calling } \\
\text { (a voice-based, real-time experience) } \\
\text { to texting (a textual, silent, and } \\
\text { asynchronous experience), rather } \\
\text { than to the industry-backed "Internet } \\
\text { everywhere" experience. }\end{array}$ \\
\hline $\begin{array}{l}\text { Firms devising new business } \\
\text { models to share texting } \\
\text { revenues with "content } \\
\text { providers" such as publishers, } \\
\text { TV broadcasters, and } \\
\text { advertisers, e.g., } \\
\text { FremantleMedia, a TV } \\
\text { company that linked up with } \\
\text { mobile firm mmO2, linking up } \\
\text { for the TV show Pop Idol that } \\
\text { operates through texting } \\
\text { audiences. }\end{array}$ & $\begin{array}{l}\text { Companies such as Zingy } \\
\text { offering ringtones and } \\
\text { logos downloadable } \\
\text { through SMS, Flytext } \\
\text { sending messages on } \\
\text { special offers from } \\
\text { shops or restaurants to } \\
\text { nearby consumers, and } \\
\text { Text Marketer Limited } \\
\text { organizing SMS-based } \\
\text { reverse auctions for } \\
\text { consumers to win } \\
\text { products at low prices. }\end{array}$ & $\begin{array}{l}\text { Field now included } \\
\text { nontelephony firms, content } \\
\text { specialists (e.g., Mobile } \\
\text { Data Group) providing } \\
\text { games downloadable } \\
\text { through SMS, Kwickee } \\
\text { offering "location aware" } \\
\text { technologies to pinpoint } \\
\text { location of users and send } \\
\text { promotional texts, Shazam } \\
\text { allowing people to identify } \\
\text { tunes heard on any sound } \\
\text { source and receive text } \\
\text { message naming the artist } \\
\text { and song title. }\end{array}$ & $\begin{array}{l}\text { Shifting user practices_-both } \\
\text { consumers and businesses; people } \\
\text { understanding mobile telephony as } \\
\text { texting rather than only calling; } \\
\text { change in societal practices such as } \\
\text { people texting rather than sending } \\
\text { postcards and birthday cards. }\end{array}$ \\
\hline $\begin{array}{l}\text { Typical revenue-sharing } \\
\text { agreement for purchase of } \\
\text { ringtones: the mobile operator } \\
(20 \%) \text {, the content provider } \\
(58 \%) \text {, the music publisher } \\
\text { and copyright owner of song } \\
\text { (12\%), and billing and sales } \\
\text { verification company (10\%) } \\
\text { (Gopinath 2005). }\end{array}$ & $\begin{array}{l}\text { All these companies had } \\
\text { no background in } \\
\text { mobile telephony and } \\
\text { were now part of the } \\
\text { organizational field of } \\
\text { mobile telephony. }\end{array}$ & $\begin{array}{l}\text { Entry of entertainment } \\
\text { companies, e.g., Endemol, } \\
\text { because of marriage of } \\
\text { mobile and media for } \\
\text { producing television shows } \\
\text { such as Pop Idol that allow } \\
\text { audience participation as } \\
\text { texting viewers vote for } \\
\text { their favorite contestants } \\
\text { (Carvajal 2005). }\end{array}$ & $\begin{array}{l}\text { Firms in constant dialogue with } \\
\text { consumers by sending text } \\
\text { messages on billing, special offers, } \\
\text { etc.; business users of mobile } \\
\text { telephony adopting texting to } \\
\text { communicate with consumers, } \\
\text { employees, and partners; } 60 \% \text { of } \\
\text { firms using it on a daily basis (Mobile } \\
\text { Data Association 2009). Examples } \\
\text { include banks texting account } \\
\text { statements, hospitals sending } \\
\text { reminders for medicine times, } \\
\text { organizations using SMS for hiring } \\
\text { and laying people off, schools and } \\
\text { universities alerting parents about } \\
\text { closures, dentists sending text } \\
\text { reminders of customer appointments, } \\
\text { charities sending texts for } \\
\text { fund-raising activities or collecting } \\
\text { donations via a text, governments } \\
\text { notifying the public about terror } \\
\text { alerts, and news channels like the } \\
\text { BBC sending breaking news alerts. }\end{array}$ \\
\hline $\begin{array}{l}\text { Mobile telephony operators } \\
\text { realigning operations for } \\
\text { texting services and vendors } \\
\text { developing new competencies } \\
\text { for producing texting-friendly } \\
\text { phones. }\end{array}$ & & $\begin{array}{l}\text { All of these actors and their } \\
\text { activities created new kinds } \\
\text { of dependencies and } \\
\text { identities in the } \\
\text { organizational field. }\end{array}$ & Major shift in core field practices. \\
\hline
\end{tabular}

industry by the conventions they created-texting via phones-causing a shift in industry emphasis from pushing new technologies to engaging and cocreating while extending existing networks (Ansari and Garud 2009). What mobile voice telephony meant therefore became contested and problematized, but the shift in organizing principles was not in the direction the industry had anticipated. Table 4 shows the three logics of mobile telephony and the associated set of practices.

\section{Discussion}

What started out as innovative consumer practices at the micro level over time enrolled other field participants as firms introduced new text-based practices and eventually 
Table 4 Three Logics of Mobile Telephony

\begin{tabular}{|c|c|c|c|}
\hline Dimension & Voice & Text & Mobile Internet \\
\hline Meaning of telephony & $\begin{array}{l}\text { Make and receive voice calls; } \\
\text { talk and listen; aural and oral } \\
\text { experience }\end{array}$ & $\begin{array}{l}\text { Exchange text messages; read and } \\
\text { write; visual experience; } \\
\text { "converse through fingers" }\end{array}$ & $\begin{array}{l}\text { "Untethering" of Internet; surf } \\
\text { Internet "on the go" through } \\
\text { mobile phone }\end{array}$ \\
\hline Purpose & Phatic & Phatic & Information and entertainment \\
\hline Temporal characteristic & Synchronous & Asynchronous & Synchronous and asynchronous \\
\hline Reach & One-to-one & One-to-one and one-to-many & $\begin{array}{l}\text { One-to-many and many-to-one } \\
\text { (broadcasting) }\end{array}$ \\
\hline $\begin{array}{l}\text { Durability of } \\
\text { conversation }\end{array}$ & No record of conversation & Record of conversation & Record of websites visited \\
\hline Impact on receiver & Intrusive for receiver & Nonintrusive for receiver & Nonintrusive for receiver \\
\hline Nature of exchange & $\begin{array}{l}\text { Intimate with verbal cues; } \\
\text { awkward in confrontational } \\
\text { situations }\end{array}$ & $\begin{array}{l}\text { Intimate with no verbal cues; useful } \\
\text { in confrontational situations }\end{array}$ & Nonintimate \\
\hline Ease of use & Very high on traditional phones & $\begin{array}{l}\text { Cumbersome to use on traditional } \\
\text { phones }\end{array}$ & $\begin{array}{l}\text { Cumbersome to use; high learning } \\
\text { costs }\end{array}$ \\
\hline Connectivity & $\begin{array}{l}\text { Restricted to close friends and } \\
\text { "quiet" surroundings; private } \\
\text { only when alone }\end{array}$ & $\begin{array}{l}\text { Ubiquitous "hyperconnectivity"; } \\
\text { suitable for "drive-by" } \\
\text { relationships and private even in } \\
\text { public settings }\end{array}$ & $\begin{array}{l}\text { Ubiquitous but impersonal; private } \\
\text { even in public settings; similar to } \\
\text { fixed Internet surfing }\end{array}$ \\
\hline $\begin{array}{l}\text { Third-party } \\
\text { involvement }\end{array}$ & No third parties & $\begin{array}{l}\text { Third parties (with permission) and } \\
\text { very limited acceptance of } \\
\text { third-party content }\end{array}$ & $\begin{array}{l}\text { Third parties with wide exposure to } \\
\text { third-party content }\end{array}$ \\
\hline $\begin{array}{l}\text { Relationship between } \\
\text { consumers and } \\
\text { mobile firms }\end{array}$ & $\begin{array}{l}\text { Proprietary relationship; central } \\
\text { "Ptolemaic" a role for mobile } \\
\text { firms }\end{array}$ & $\begin{array}{l}\text { Relationship shared with limited } \\
\text { number of third parties; } \\
\text { "Copernican"b role for mobile } \\
\text { firms }\end{array}$ & $\begin{array}{l}\text { Relationship shared with wide } \\
\text { variety of third parties; } \\
\text { "Copernican" role for mobile firms }\end{array}$ \\
\hline
\end{tabular}

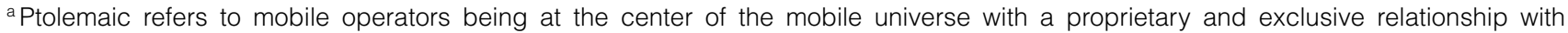
consumers.

${ }^{b}$ Copernican refers to mobile operators not being at the center with an exclusive relationship with consumers but having to share consumer revenues with third parties (content providers).

catalyzed a virtual cycle of field change. This sort of innovation in use by consumers is not, in itself, surprising. Given their weight of numbers and deep knowledge about the contexts of use, users may even have a "comparative advantage over manufacturers as a source of innovations in use" (Faulkner and Runde 2009, p. 456; von Hippel 2005). However, as we noted earlier, consumers do not always play an innovative role nor do their activities always lead to field-level change. What, then, are the conditions under which consumers innovate? And what conditions lead their innovations to catalyze field-level changes? We identified two conditions that increase the likelihood that consumers will innovate in this way: low experimentation costs and cultural readiness. We also identified two conditions that increase the likelihood that these innovations will lead to fieldlevel changes: practice stickiness and the degree of practice compatibility with firm-sponsored projects, leading to subsequent support from industry firms. We will discuss these conditions in turn.

\section{Conditions Leading to Innovative Consumer Practices}

Low experimentation costs refer to the initial ease of engaging with a product and its ready availability. Low experimentation costs encourage bricolage among consumers. In our case, almost everyone already had an SMS-capable phone, and sending one's first text on a familiar device was not particularly cognitively taxing. In contrast, WAP was not easy to experiment with. Consumers not only needed to pay for access to WAPbased content but also found it difficult to configure and use their phones for Internet browsing. Furthermore, although everyone had a GSM connection with an SMS option, consumers needed to subscribe to WAP to access content on their mobile phones.

Low experimentation costs allowed consumers to take control of the SMS technology and make it meaningful for them, as they developed texting-specific codes and symbols. On the other hand, although WAP offered superior functionality from a technological standpoint, high costs of experimentation made it difficult for consumers to engage with it and innovate in ways that made it socially meaningful. Thus, despite being based on what was in many ways an inferior technology compared with WAP and offering limited technical functionalities, SMS was easy to trial, learn, and experiment with, and consumers were therefore more likely to innovate around it. A similar argument could be made for explaining 
the rapid diffusion of file sharing among Internet consumers worldwide. Copying and sharing files involved low experimentation costs, and the practice quickly spread among other consumer groups as they innovated new ways to use it and new communities formed around the technology. We summarize our arguments in the form of a proposition.

Proposition 1. Consumers are more likely to develop innovative practices around a product when there are low experimentation costs - that is, low cognitive costs and ready availability-associated with its use.

The second factor we identified was the critical role of the macrocultural context, what we term "cultural readiness." From our analysis, the influence of the macrocultural context, and in particular the "institutional conditions operating in the broader societal field" (Strang and Meyer 1993, p. 487), is particularly important because they can enable consumers to socially construct products in innovative ways or, equally, make this sort of innovation unlikely. Whatever the nature of the product or service, how it is interpreted, understood, and used by various consumers is related to the broader societal environment in which it is embedded. Indeed, societal factors "provide a repertoire of capacities" (Swidler 1986, p. 282) and the "important raw materials from which actors can fashion new patterns of activity and new relationships" (Lawrence and Phillips 2004, pp. 691-692). They also set boundaries on the degree of innovation around practices possible within a field.

In our case, we were able to observe how certain social developments provided "demonstration events" (Suchman 1995) that were crucial to consumers innovating and building new practices around SMS, and that also made it unlikely that consumers would innovate around WAP in the same way. It is worth noting that before SMS emerged, mobile voice telephony had already become widespread, liberating people from the constraints of physical copresence and spatial anchoring associated with fixed-line telephony. The mobile phone had contributed to the reorganization of the sites of social interaction-work and leisure-making the prearranged structure of the everyday life more fluid, with daily life an intermingling of working hours and leisure time, and urban space becoming more of a "common living room" (Kopomaa 2000). Furthermore, with the widespread use of e-mail and instant messaging, people had become used to communicating through text rather than voice in an increasingly dispersed and mobile society that needed to be perpetually connected through devices (Katz and Aakhus 2002). This development set the stage for further developments in text-based mobile communication.

In addition, the Internet had contributed to an increase in user control, allowing users to circumvent various forms of authority through a vast transformation in who governs information and experiences (Rheingold 2002). Consumers, and in particular younger users, had also become increasingly used to openness, participation, and interactivity in workplaces and communities. Although the Internet had become an important social space, the limitations of WAP did not fit with the expectations of consumers. Because consumers had wanted to connect, share, socialize, and express themselves through their mobile phones rather than be passively informed or entertained by prefabricated Internet content that they could not modify or interact with, SMS resonated with the need for increased social or "phatic" connectivity with "absent" others far more than WAP. Therefore, among the two competing data-based logics in the mobile telephony field, texting and mobile Internet, the cultural context was more conducive to the development and adoption of texting despite the fact that texting was developed around a technically "inferior" SMS technology compared with the "superior" WAP that was supported by industry firms.

In short, prior developments in the social context had set the stage for consumers to cultivate particular innovative practices resonant with those developments around SMS and not WAP. Generalizing from our case, consumers are therefore more likely to develop novel practices around products when there is a conducive societal context. Stated as a proposition,

Proposition 2. Consumers are more likely to develop innovative practices around a product when there is a high degree of cultural readiness for it in the broader societal context.

But even when consumers innovate and develop new practices around a product, it does not always lead to field-level changes. Under what conditions do innovative consumer practices catalyze field-level changes? We identified two conditions that we discuss in the next section.

\section{Conditions Leading Consumer Innovations to Catalyze Field-Level Change}

The first condition that increases the likelihood that innovative practices will catalyze field-level change pertains to the nature of the practice itself: for an innovative practice to generate field-level changes, it needs to be deeply and compellingly entrenched in social life. An important aspect of consumer innovation that emerged from our analysis was that once consumers began texting, it was very difficult for them to abandon it. We refer to this aspect of a new practice as "stickiness"- the tendency for its use to become irreversible. Unlike the economic arguments around "lock-in" effects that involve high costs of switching from an established product (e.g., Schilling 2002), stickiness refers to the fact that changes in social practice related to adoption may be difficult to 
reverse because of their interrelationships with broader sets of related social practices. As one "textaholic," a 21-year-old student, noted, "I admit to being a serial texter. Texting is addictive. There is no going back. Once you start texting, you never stop."

Many consumers of text messages described rapidly becoming accustomed to what has been called "hypercoordination" (Katz and Aakhus 2002) - remaining in perpetual contact and managing complex social plans through the constant arrangement and rearrangement of logistical details on the fly. The expectation of this sort of interaction among group members then made texting essential to the ongoing functioning of their social group. Once the expectation, for instance, of being able to manage logistical details on the fly was deeply embedded and traditional practices of managing a social group forgone (such as precise details about places and times to meet communicated well beforehand), there was no way to easily revert to practices that predated texting. Because of the formation of implicit social contracts and the increased pace of social coordination among members, once groups start texting they became dependent on the practice, and no individual could quit or revert to previous practices. Texting is therefore a highly sticky practice and more likely to catalyze field change.

On the other hand, although some consumers used WAP sporadically, it did not have the same level of stickiness. People would occasionally browse the Internet through their mobile phones, but they experienced little social pressure to continue to engage in the practice. Therefore, we argue that institutionalized practices that are sticky are more likely to trigger field-level changes. Stated as a proposition,

Proposition 3. Practices that lead to difficult-toreverse changes in patterns of social interaction-that are sticky-are more likely to lead to field-level change.

The second condition we identified that increased the likelihood of consumer practices generating field-level change is the degree of incompatibility of the innovative practice with the institutional projects of industry firms and subsequent support from some new or preexisting organizations. It is only in the case where there is some incompatibility between the practices innovated by consumers and the projects of core incumbents that consumers can be a catalyst for change, but without some support from organized actors, their activity cannot generate significant pressure for change. Only when their practices are incompatible and there is support from new or more peripheral organizations would we expect change to be catalyzed.

As we noted earlier, in many cases it is not consumers who develop innovative practices. In many instances, it is organizational actors that "educate" consumers to adopt novel practices. This was seen in the classic "institutional entrepreneurship" of Kodak in the emerging field of photography as the firm created subject positions for consumers to preserve memories of special occasions (Munir and Phillips 2005). In other instances, consumers innovate on their own, but their innovations are aligned with the institutional project of firms, and there is little reason that their activities would disrupt existing fieldlevel arrangements. Examples include user-led innovations in the design of surfboards and mountain bicycles and in the discovery of "off-label" uses for pharmaceutical drugs (von Hippel 2005) that complement rather than disrupt the broader innovation efforts of the industry.

However, in some instances, and as we found in the case of texting, consumers may bring a different understanding to the use of a product from what the producers had intended and innovate in a manner that conflicts with the incumbents' institutional projects. For example, Faulkner and Runde (2009) document the episode of how innovation in use led to the transformation of the gramophone turntable from being a device for playing prerecorded music into being a musical instrument, as "turntablists" used the product to create new music by physically manipulating vinyl records under a turntable stylus. Although manufacturers had sought to phase out turntables and vinyl records in the age of digital products, this consumer-led innovation revitalized a dying product and triggered several changes in the field. Because firms may not be initially prepared for these unanticipated changes, they are likely to, at least initially, resist change and instead continue promoting their own institutional project, as we saw in the case of WAP (mobile Internet). However, as the texting case illustrates, firms may eventually be pressed into changing course by the collective pressure of consumer actions, leading to field-level changes.

Incompatibility with industry-sponsored projects is, however, a necessary but not a sufficient condition for catalyzing field-level change. Indeed, change is only likely to happen if the practices not only diffuse among a sizable number of consumers and other field constituents but also become institutionalized as the standard way to act in particular situations. However, innovative practices are unlikely to become institutionalized and to generate the kind of pressure required for field-level change if they remain limited to consumers and do not receive support from organized actors of some kind.

In our case, as our three-phase model shows, the practice of texting became institutionalized with support from organized actors, both new entrants and, later, industry incumbents that collectively generated pressure for changes in the field. Consumer innovations therefore need to be eventually aligned with the interests of some organized field actors-either start-ups, marginal players, dominant incumbents, or the government-to get the kind of social and technological support needed to generate field-level changes. Therefore, in addition to 
innovative practices being incompatible with firms' institutional projects, these practices also need subsequent support from at least some of the organized actors in the field to begin to catalyze field-level change. Stated as a proposition,

Proposition 4. If consumer innovative practices are incompatible with the institutional projects of incumbent firms and receive subsequent support from some organized actors in the field, they are more likely to catalyze field-level change.

It is important to note that our general observation that consumers are active participants in shaping products and services, rather than passive recipients in adopting them, is not just limited to SMS. Indeed, there has recently been a phenomenal rise in the popularity of organizations that are based on user-generated content: online encyclopedias (e.g., Wikipedia), videosharing platforms (e.g., YouTube), social networking Internet sites (e.g., Facebook and Twitter ${ }^{6}$ ), and rating systems such as TripAdvisor, toptable, and Zagat-all based on participating consumers. These developments, no doubt encouraged by an increasingly digitized and networked environment that facilitates communication among dispersed users (Rheingold 2002), carry important implications for organizational fields and the incumbent organizations at the centre of them. They also have important ramifications for institutional theory, and further research and theorizing on the effects of this trend and the increasingly central role of consumers in institutional processes are needed.

\section{Conclusions and Implications}

Although the concept of institutional entrepreneurship has contributed significantly to our understanding of field-level change, it has also tended to focus discussions overly narrowly on the actions of certain organized and purposeful actors. In particular, the part played by unorganized groups, such as consumers, in change has received little attention in the literature. We begin to redress the balance by conceptualizing the role of consumers in creating and diffusing new practices and collectively impacting a field by implicating other field constituents.

At the same time, we realize that bringing consumers "back in" is a thorny intellectual move relative to the foundations of institutional theory that argued against an overly narrow focus on how consumer preferences shape markets. We are not arguing for a return to these earlier approaches, but rather that there are important institutional aspects to the activities of consumers and that consumer action matters in creating new practices and catalyzing field-level change, even when the top-down efforts of other formally organized field constituents have been accounted for.
Understanding the role of consumers, especially a consumer with an ever-growing cocreative role in increasingly networked environments, is also in line with recent work in other theoretical streams, such as increasing interest in consumers in strategic management (Priem 2007). It also addresses the call to bring consumers into the study of management and organizations that "has been handicapped by a dominant ideological orientation" that has not included them (Brief and Bazerman 2003, p. 187). Other literatures such as the technology studies literature (e.g., Orlikowski 2000), the social construction of technology literature (e.g., Bijker and Law 1997), diffusion theories (e.g., Rogers 2003), and strategy and economics (e.g., Christensen 1997) have explored the active role of consumers, including the role of "lead users," and more recently user communities (e.g., von Hippel 2005), in influencing processes of innovation and change. A field-analytic institutional approach for examining innovation draws attention to the social dynamics of the process and to the beliefs and behaviors of a variety of field participants, including consumers, and to how consumer actions may collectively lead to changes in an organizational field.

This is not to suggest consumers change fields by themselves. In our case, it was, after all, the producers that provided the product and mobile communications system while other new organizations encouraged its use by developing complementary products and services. However, it was consumer innovation that resulted in the practice becoming widely established, despite the absence of price reductions, the initial lack of industry promotion, and the existence of technically superior alternatives. The industry then built on these consumer innovations to develop scalable products around the practice that sat alongside its other product offerings and that led to important changes in the field.

But how does change catalyzed by consumers differ from change led by noncore actors where innovations are initially adopted by those at the margins (e.g., Leblebici et al. 1991)? First, in our case, the incumbents were not inertial or seeking to preserve the status quo. Rather, wedded to widely held belief about the industry's future, they sought a different kind of change from the one that ensued. Second, unlike noncore actors that are often driven by an institutional agenda, innovative consumer activities are driven by more personal goals such as the search for autonomy and identity or the solution of practical problems, and the resulting change is an unintended effect of their activities. Finally, consumer-led field changes may not necessarily be characterized by contestation to the same degree as industry-led changes. Such struggles often occur when more purposeful actors come into conflict, such as when actors at the periphery threaten to capture part of the incumbents' turf or when regulators pass laws that undermine incumbent domination. Because consumers forge cultural worlds through 
the pursuit of shared consumption interests, the product or set of practices may become accepted and legitimate among large swathes of consumers without explicit endeavors from organized actors.

We believe that in making these arguments, this paper makes important contributions to institutional theory. First, we argue for the need to balance the strong focus on purposeful or "heroic" acts of institutional entrepreneurship (Garud et al. 2007) that have come to dominate discussions of field-level change. We discuss how the influence of innovative activities of dispersed and unorganized agents in catalyzing change is an alternative explanation of change in institutional theory that does not privilege purposeful actors such as institutional entrepreneurs. Second, we illustrate how new practices emerge and diffuse through the everyday activities of consumers as they socially construct new practices around which other constituents then coalesce, leading to broader field-level changes. Our study thus provides some insight into these micro-macro linkages by explaining how microlevel activity innovations create new practices that catalyze changes at the field level. Future studies can examine how wider social and cultural developments, rather than new products and technologies, influence various field constituents and drive innovation processes and the evolution of novel practices and changes in a field.

\section{Acknowledgments}

The authors gratefully acknowledge the constructive comments of their editor, Samer Faraj, and three anonymous reviewers. They also thank participants at European Group for Organization Studies (EGOS) 2005 and Organization Theory Research Group (OTREG) 2007, where earlier versions of this paper were presented. They are also grateful to Michael Lounsbury, Anand Narasimhan, and Eric Abrahamson for their helpful suggestions. S. Ansari is also an assistant professor at the Rotterdam School of Management, Erasmus University, Rotterdam, the Netherlands.

\section{Endnotes}

${ }^{1}$ In the literature, diffusion and institutionalization are often closely associated, with institutionalization "operationalized by prevalence or increasing diffusion within a given population of organizations rather than through direct assessments of 'taken-for-grantedness' by aggregates of relevant actors" (Green 2004, p. 657). In this article, we use "diffusion" to refer to the process of increasing adoption and use of a practice (Rogers 2003); we use "institutionalization" to refer to the process of the practice becoming deeply entrenched, a part of the cognitive repertoire and the accepted norms, such "that abandonment of it is unlikely" (Zeitz et al. 1999, p. 743). The widely diffused practice of text messaging could be seen as likely to endure - an everyday taken-for-granted and widely accepted way of communicating for over $80 \%$ of the United Kingdom's population.

${ }^{2}$ Later in the year 2000 , the UK government held the first Universal Mobile Telecommunications System (3G) spectrum auctions in Europe, raising an unprecedented $\$ 35$ billion from the sale of five licenses to acquire new third-generation mobile technologies in what was described at the time by the Economist as the "biggest gamble in business history" (Ansari and Munir 2008, p. 301).

${ }^{3}$ Although a lack of WAP-enabled handsets, problems in configuring phones and downloading Internet content, and a "walled garden" approach that limited access to Internet content contributed to WAP's failure, adoption remained very limited even when the technology later improved.

${ }^{4}$ Network externalities, whereby the value of using a product or a technology increases with the addition of nodes to the network of connections (Katz and Shapiro 1985), played a role in fueling adoption because increasing adoption made adoption more attractive.

${ }^{5}$ www.text.it; www.textprefs.com; www.textually.org; www.funsms .net; www.bbc.co.uk; www.centrifugalforces.co.uk; www.clubnokia .co.uk; www.MyAlert.com; www.simplywireless.com; www.telecom.com; www.uboot.com; www.wapforum.org; www.wapinsight.com; www .Zdnetuk.co.uk.

${ }^{6}$ It is worth noting that SMS acted as a demonstration event for Twitter, which features 140-character "tweets" or microblogs rather than whole stories to stay hyperconnected with friends.

\section{References}

Ahonen, T. 2009. Tomi Ahonen Almanac 2009-Mobile Telecoms Industry Review. TomiAhonen Consulting. http://www .tomiahonen.com

Ansari, S., R. Garud. 2009. Inter-generational transitions in sociotechnical systems: The case of mobile communications. Res. Policy 38(2) 382-392.

Ansari, S., K. Munir. 2008. How valuable is a piece of the spectrum? Determination of value in external resource acquisition. Indust. Corporate Change 17(2) 301-333.

Aoki, M. 2001. Toward a Comparative Institutional Analysis. MIT Press, Cambridge, MA.

Baker, S., M. Clifford. 2002. Tale of a bubble: How the 3G fiasco came close to wrecking Europe. Bus. Week (June 3), http://www .businessweek.com/magazine/content/02_22/b3785010.htm.

Barley, S. R., P. S. Tolbert. 1997. Institutionalization and structuration: Studying the links between action and institution. Organ. Stud. 18(1) 93-117.

Baron, S., A. Patterson, K. Harris. 2006. Beyond technology acceptance: Understanding consumer practice. Internat. J. Service Indust. Management 17(2) 111-135.

Benson, R. 2000. The joy of text. Guardian (June 3), http://women .timesonline.co.uk/tol/life_and_style/women/relationships/article -1720309.ece.

Bijker, W., J. Law. 1997. Shaping Technology/Building Society: Studies in Sociotechnical Change. MIT Press, Cambridge, MA.

Brief, A. P., M. Bazerman. 2003. Editor's comments: Bringing in consumers. Acad. Management Rev. 28(2) 187-189.

Carphone Warehouse. 2006. The mobile life report 2006: How mobile phones change the way we live. London School of Economics and Political Science/Carphone Warehouse, http://www .mobilelife2006.co.uk.

Centre for Economics and Business Research. 2004. The changing economic impact of mobile phones. Report, $\mathrm{mmO} 2$, Berkshire, UK. 
Christensen, C. M. 1997. The Innovator's Dilemma: When New Technologies Cause Great Firms to Fail. Harvard Business School Press, Cambridge, MA

Crabtree, J., M. Nathan, S. Roberts. 2003. Mobile UK: Mobile phones and everyday life. Report, The Work Foundation, London.

Dacin, M. T., J. Goldstein, W. R. Scott. 2002. Institutional theory and institutional change: Introduction to the special research forum. Acad. Management J. 45(1) 43-56.

Davis, G. F., C. Marquis. 2005. Prospects for organization theory in the early twenty-first century: Institutional fields and mechanisms. Organ. Sci. 16(4) 332-343.

Delbridge, R., T. Edwards. 2008. Challenging conventions: Roles and processes during non isomorphic institutional change. Human Relations 61(3) 299-325.

Denzin, N. K., Y. S. Lincoln. 2000. Handbook of Qualitative Research. Sage, Thousand Oaks, CA.

DiMaggio, P. 1988. Interest and agency in institutional theory. L. G. Zucker, ed. Institutional Patterns and Organizations: Culture and Environment. Ballinger, Cambridge, MA, 3-22.

DiMaggio, P. J., W. W. Powell. 1983. The iron cage revisited: Institutional isomorphism and collective rationality in organizational fields. Amer. Sociol. Rev. 48(2) 147-160.

Dorado, S. 2005. Institutional entrepreneurship, partaking, and convening. Organ. Stud. 26(3) 385-414.

Economist, The. 2004. Mobile phones: Battling for the palm of your hand. (April 29), http://www.economist.com/node/2628495.

Eisenhardt, K. M. 1989. Building theories from case study research. Acad. Management Rev. 14(4) 532-550.

Farjoun, M. 2002. The dialectics of institutional development in emerging and turbulent fields: Pricing conventions in the online database industry. Acad. Management J. 45(5) 848-874.

Faulkner, P., J. Runde. 2009. On the identity of technical objects and user innovations in function. Acad. Management Rev. 34(3) $442-462$.

Fortunati, L. 2002. The mobile phone: Towards new categories and social relations. Inform., Comm. Soc. 5(4) 513-528.

Fox, K. 2001. Evolution, alienation and gossip: The role of mobile telecommunications in the 21st century. Report, Social Issues Research Centre, London. http://www.sirc.org/publik/ gossip.shtml.

Friedland, R., R. R. Alford. 1991. Bringing society back in: Symbols, practices, and institutional contradictions. W. W. Powell, P. J. DiMaggio, eds. The New Institutionalism in Organizational Analysis. University of Chicago Press, Chicago, 232-263.

Galvin, T. L., M. J. Ventresca, B. A. Hudson 2005. Contested industry dynamics. New directions in the study of legitimacy. Internat. Stud. Management Organ. 34(4) 56-82.

Gartner. 2006. Gartner's top predictions for IT organizations and users 2007 and beyond. Report, Gartner, Stamford, CT.

Garud, R., C. Hardy, S. Maguire 2007. Institutional entrepreneurship as embedded agency: An introduction to the special issue. Organ. Stud. 28(7) 1101-1122.

Giussani, B. 2001. Roam: Making Sense of the Wireless Internet. Random House, London.

Glaser, B. G., A. L. Strauss. 1967. The Discovery of Grounded Theory: Strategies of Qualitative Research. Weidenfeld \& Nicolson, London.

Goggin, G., C. Spurgeon. 2007. Premium rate culture: The new business of mobile interactivity. New Media Soc. 9(5) 753-770.
Gopinath, S. 2005. Ringtones, or the auditory logic of globalization. First Monday 10(12) 1-54.

Green, S., Jr. 2004. Rhetorical theory of diffusion. Acad. Management Rev. 29(4) 653-669.

Greenwood, R., R. Suddaby. 2006. Institutional entrepreneurship in mature fields: The Big Five accounting firms. Acad. Management J. 49(1) 27-48.

Haig, M. 2002. Mobile Marketing: The Message Revolution. Kogan Page, London.

Hargadon, A. B., Y. Douglas. 2001. When innovations meet institutions: Edison and the design of the electric light. Admin. Sci. Quart. 46(3) 476-501.

Hargrave, T. J., A. H. Van de Ven. 2006. A collective action model of institutional innovation. Acad. Management Rev. 31(4) 864-888.

Harkins, J. 2003. Mobilization: The growing public interest in mobile technology. Report, Demos, London.

Hensmans, M. 2003. Social movement organizations: A metaphor for strategic actors in institutional fields. Organ. Stud. 24(3) $355-381$.

Hutchby, I. 2001. Conversation and Technology: From the Telephone to the Internet. Blackwell Publishers, Cambridge, UK.

International Telecommunication Union. 2009. Corporate Annual Report 2009. ITU, Geneva.

Katz, J. E., M. A. Aakhus, eds. 2002. Introduction: Framing the issues. Perpetual Contact: Mobile Communication, Private Talk, Public Performance. Cambridge University Press, Cambridge, UK, 1-14.

Katz, M. L., C. Shapiro. 1985. Network externalities, competition, and compatibility. Amer. Econom. Rev. 75(3) 424-440.

Kaufman, J., O. Patterson. 2005. Cross-national cultural diffusion: The global spread of cricket. Amer. Sociol. Rev. 70(1) 82-110.

Kopomaa, T. 2000. The City in Your Pocket: Birth of the Mobile Information Society. Gaudeamus, Helsinki.

Kvale, S. 1996. InterViews: An Introduction to Qualitative Research Interviewing. Sage, Thousand Oaks, CA.

Lacohée, H., N. Wakeford, I. Pearson. 2003. A social history of the mobile telephone with a view of its future. BT Tech. J. 21(3) 203-211.

Lampel, J., A. Meyer, M. Ventresca. 2005. Field-configuring events as structuring mechanisms: How conferences, ceremonies, and trade shows constitute new technologies, industries, and markets. J. Management Stud. 42(5) 1099-1100.

Lawrence, T. B., N. Phillips. 2004. From Moby Dick to Free Willy: Macro-cultural discourse and institutional entrepreneurship in emerging institutional fields. Organization 11(5) 689-711.

Lawrence, T. B., R. Suddaby. 2006. Institutions and institutional work. S. Clegg, C. Hardy, T. B. Lawrence, W. R. Nord, eds. The Sage Handbook of Organization Studies. Sage, London, 215-254.

Lawrence, T. B., C. Hardy, N. Phillips. 2002. Institutional effects of interorganizational collaboration: The emergence of protoinstitutions. Acad. Management J. 45(1) 281-290.

Leblebici, H., G. R. Salancik, A. Copay, T. King. 1991. Institutional change and the transformation of interorganizational fields: An organizational history of the U.S. radio broadcasting industry. Admin. Sci. Quart. 36(3) 333-363.

Lincoln, Y. S., E. G. Guba. 1985. Naturalistic Inquiry. Sage, Newbury Park, CA.

Locke, K. D. 2001. Grounded Theory in Management Research. Sage, London. 
Lounsbury, M., E. T. Crumley. 2007. New practice creation: An institutional perspective on innovation. Organ. Stud. 28(7) 993-1012.

Maguire, S., C. Hardy. 2008. Institutional entrepreneurship. R. Greenwood, R. Suddaby, C. Oliver, K. Sahlin Andersson, eds. The Sage Handbook of Organizational Institutionalism. Sage, Thousand Oaks, CA, 198-217.

Marshall, P. D. 2004. New Media Cultures. Edward Arnold, London.

Menon, N., M. Page, M. Watt, S. Bell. 2005. Mobinet 2005: An A. T. Kearney/University of Cambridge Study. Survey, A. T. Kearney, London; and University of Cambridge, Cambridge, UK.

Meyer, A. D. 1982. Adapting to environmental jolts. Admin. Sci. Quart. 27(4) 515-537.

Miles, M. B., A. M. Huberman. 1994. Qualitative Data Analysis: An Expanded Sourcebook, 2nd ed. Sage, Thousand Oaks, CA.

Mobile Data Association. 2009. Latest statistics. Press release (March 4). Retrieved August 13, 2009, http://www.themda.org/.

Munir, K. A., N. Phillips. 2005. The birth of the "Kodak moment": Institutional entrepreneurship and the adoption of new technologies. Organ. Stud. 26(11) 1665-1687.

Munir, K., M. Jones, W. Orlikowski, J. Runde, L. Nikolychuk. 2007. From photos to pixels. Micro-institutional dynamics in institutional change. Presentation, Academy of Management Conference, August 2-7, Philadelphia.

Office of Communications. 2009. The communications market. Report, Office of Communications, London.

Orlikowski, W. J. 2000. Using technology and constituting structures: A practice lens for studying technology in organizations. Organ. Sci. 11(4) 404-428.

Patton, M. Q. 2002. Qualitative Research and Evaluation Methods. Sage, Thousand Oaks, CA.

Pettigrew, A. M. 1990. Longitudinal research on change: Theory and practice. Organ. Sci. 1(3) 267-292.

Plant, S. 2000. On the mobile: The effect of mobile telephones on social and individual life. Retrieved September 10, 2005, http:// www.motorola.com/.

Priem, R. L. 2007. A consumer perspective on value creation. Acad. Management Rev. 32(1) 219-235.

Rao, H. 2009. Market Rebels: How Activists Make or Break Radical Innovations. Princeton University Press, Princeton, NJ.

Rao, H., P. Monin, R. Durand. 2003. Institutional change in Tocque Ville: Nouvelle cuisine as an identity movement in French gastronomy. Amer. J. Sociol. 108(4) 795-843.

Rao, H., C. Morrill, M. N. Zald. 2000. Power plays: How social movements and collective action create new organizational forms. Res. Organ. Behav. 22 237-282.

Reay, T., C. R. Hinings. 2009. Managing the rivalry of competing institutional logics. Organ. Stud. 30(6) 629-652.

Rheingold, H. 2002. Smart Mobs. The Next Social Revolution. Perseus Publishing, Cambridge, MA.

Rogers, E. M. 2003. The Diffusion of Innovations, 5th ed. Free Press, New York.

Sanders, W. G., A. Tuschke. 2007. The adoption of institutionally contested organizational practices: The emergence of stock option pay in Germany. Acad. Management J. 50(1) 33-56.

Sarin, A. 2006. The role of mobile phones in increasing accessibility and efficiency in healthcare. Vodafone Policy Paper 4 (March 24), Vodafone, Newbury, UK
Sauder, M. 2008. Interlopers and field change: The entry of U.S. news into the field of legal education. Admin. Sci. Quart. 53(2) 209-234.

Schatzki, T. R., K. Knorr Cetina, E. von Savigny, eds. 2001. The Practice Turn in Contemporary Theory. Routledge, London.

Schilling, M. A. 2002. Technology success and failure in winnertake-all markets: The impact of learning orientation, timing and network externalities. Acad. Management J. 45(2) 387-398.

Schneiberg, M. 2005. Combining new institutionalisms: Explaining institutional change in American property insurance. Sociol. Forum 20(1) 93-137.

Scott, W. R. 2001. Institutions and Organizations. Sage, Thousand Oaks, CA.

Seo, M., W. E. D. Creed. 2002. Institutional contradictions, praxis and institutional change: A dialectical perspective. Acad. Management J. 27(2) 222-247.

Stern, B. B. 1994. A revised communication model for advertising: Multiple dimensions of the source, the message and the recipient. J. Advertising 23(2) 5-15.

Strang, D., J. W. Meyer. 1993. Institutional conditions for diffusion. Theory Soc. 22(4) 487-511.

Suchman, M. C. 1995. Managing legitimacy: Strategic and institutional approaches. Acad. Management Rev. 20(3) 571-610.

Swidler, A. 1986. Culture and action: Symbols and strategies. Amer. Sociol. Rev. 51(2) 273-286.

Taylor, A. S., R. Harper. 2003. The gift of the gab? A design oriented sociology of young people's use of mobiles. Comput. Supported Cooperative Work 12(3) 267-296.

Taylor, A. S., J. Vincent. 2005. An SMS history. L. Hamil, A. Lasen, eds. Mobile World: Past, Present and Future. Springer, New York, 75-92.

Van de Ven, A. H., D. E. Polley, R. Garud, S. Venkataraman. 1999. The Innovation Journey. Oxford University Press, New York.

von Hippel, E. 2005. Democratizing Innovation. MIT Press, Cambridge, MA.

Weick, K. E., K. M. Sutcliffe, D. Obstfeld. 2005. Organizing and the process of sensemaking. Organ. Sci. 16(4) 409-421.

Yin, R. K. 1993. Applications of Case Study Research. Sage, London.

Zeitz, G., V. Mittal, B. McAulay. 1999. Distinguishing adoption and entrenchment of management practices: A framework for analysis. Organ. Stud. 20(5) 741-776.

Shahzad (Shaz) Ansari is a university lecturer in strategy at the Judge Business School, University of Cambridge, and a visiting assistant professor at the Rotterdam School of Management, Erasmus University. His research interests include institutional change in public and private fields including climate change, technological and management innovations, knowledge management, new market development, inclusive growth and social value creation, and outsourcing and offshoring.

Nelson Phillips is a professor of strategy and organizational behavior at Imperial College London, where he is also head of the Organization and Management Group. His research interests include various aspects of organization theory, technology, and entrepreneurship, generally studied from an institutional perspective. He also has an interest in discourse analysis and related textual research methods. He has published numerous academic articles and book chapters and has also written three books. 